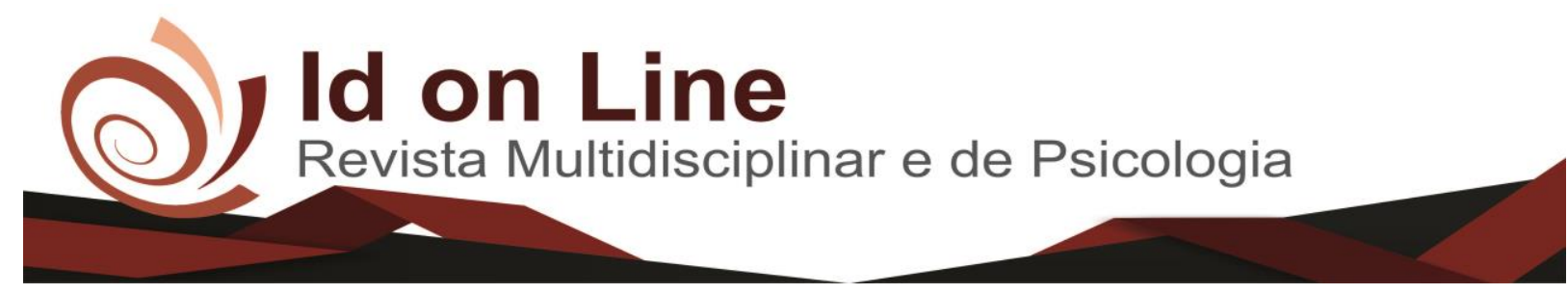

Comment

\title{
Tecnologia Assistiva para uma Escola Inclusiva: Desafios e Perspectivas
}

\author{
Simone dos Santos Alencar ${ }^{1}$; Aurenia Pereira de França ${ }^{2}$
}

Resumo: A abordagem apresentada neste artigo tem como temática a Tecnologia Assistiva para Escola Inclusiva, a qual seu maior desafio é ofertar à acessibilidade para as pessoas com deficiência, garantindo igualdade de condições com os demais. Objetivando analisar a contribuição da tecnologia assistiva na inclusão de crianças em ambiente escolar. Este estudo torna-se propício para as atividades das crianças, com algum tipo de deficiência. A metodologia utilizada para desenvolver o presente estudo é de ordem bibliográfica e qualitativa. Os teóricos que fundamentam essa pesquisa são: Miranda (2006), Galvão (2004), Kleiman (2007), entre outras fontes. Observouse que é de grande relevância o processo de apropriação e uso da tecnologia assistiva. A fim de melhorar a qualidade de vida de todas as pessoas, para que sejam vistas de forma inclusiva diante da sociedade.

Palavras-chave: Educação Inclusiva. Tecnologia Assistiva. Educação Infantil. Acessibilidade. Ensino Aprendizagem.

\section{Assistive Technology for an Inclusive School: Challenges and Perspectives}

\begin{abstract}
The approach presented in this article has the theme Assistive Technology for Inclusive School, aiming to analyze the contribution of assistive technology in the inclusion of children in the school environment, with the assiduous participation of teachers, to choose an appropriate environment and conducive to the activities of children, with some kind of disability. The methodology used to develop the present study is of bibliographic and qualitative order. The theorists who base this research are: Miranda (2006), Galvão (2004), Kleiman (2007), among other sources. It was observed that the process of appropriation and use of assistive technology is of great relevance.
\end{abstract}

Keywords. Inclusive education. Assistive Technology. Childhood Education.Accessibility

\section{Introdução}

A Educação Inclusiva é um processo deflagrado na década de (90), noventa que evidencia que todos os alunos com ou sem deficiência, devem e podem frequentar o mesmo espaço escolar com o intuito de aprender e socializar-se junto das outras crianças consideradas normais.

\footnotetext{
1 ALENCAR, Simone, Santos. Graduanda em Pedagogia. Faculdade Ciências Humanas do Sertão Central-FACHUSC. Contato: simonesa1@outlook.com;

${ }^{2}$ FRANÇA, Aurenia, Pereira. Esp. Em Metodologia do Ensino. Esp. Em Ciências da Educação e Supervisão Pedagógica e Mestranda em Ciências da Linguagem - UNICAP
} 
A Política Nacional de Educação Inclusiva (MEC-2008) reforça tais pressupostos, dando deliberações e determinando que o público alvo da Educação Inclusiva seja assistido com responsabilidade e prioridade. Dentre esses alunos destacam as crianças com Transtorno Global (TGD) e as crianças Autista. As realidades referentes à pessoa com deficiência ainda são bastante desconhecidas da população em geral, em muitos casos a família não tem conhecimento algum dos direitos assistidos as crianças portadoras de algum tipo de deficiência.

Mesmo com o país dispondo de uma legislação relativa aos direitos da pessoa com deficiência considerada avançada internacionalmente, e a sociedade atual venham tomando consciência de todos os seus direitos, muito ainda precisa ser feito para que tenhamos em nossas escolas equipamentos qualificados para uso exclusivo das crianças que realmente necessita desses aparelhamentos, que ainda está escasso nas nossas escolas.

Este artigo elenca pontos, que priorizam a importância da família na educação inclusiva dos seus filhos, que necessitam de um cuidado especializado, contribuindo diretamente para a construção da identidade da criança portadora de alguma deficiência. , ressaltando ainda, a importância das tecnologias assistivas, que é fundamental para o desenvolvimento das crianças com deficiência. A presente pesquisa traz pontos que contribui de forma significativa para o reconhecimento real dos direitos das crianças junto à família que é a parte fundamental para um bom desempenho do aluno, tanto na sala de aula ou fora dela. Mesmo com tantos avanços tecnológicos precisamos está atenta em tudo que diz respeito ao desenvolvimento infantil da criança e trazer para a realidade com o intuito de buscar melhorias na parceria família e escola, e órgãos relacionados à inclusão e tecnologias assistivas no ambiente escolar. Assegurando-lhe o direito a inclusão assistiva diante de uma sociedade mais justa. Garantir que estes alunos sejam oportunizados conforme sua deficiência.

Deste modo, faz-se necessário apresentar a problemática deste estudo através dos seguintes questionamentos: Onde buscar essas tecnologias assistivas? Como ter acesso a elas? Como é visto esses alunos na escola.

Diante disso destaca-se o objetivo geral: compreender a relevância da inclusão e das técnicas assistivas no espaço escolar, favorecendo a aprendizagem, a segurança e a formação da identidade do menor. E como específico: incluir a criança nas salas de aula do ensino regular, dando-lhe assistência no que for necessário. Assegurando-lhe o direito a inclusão assistiva diante de uma sociedade mais justa. Garantir que estes alunos sejam oportunizados conforme sua deficiência. Este documento se apresenta sobre as forma de tópicos, onde o segundo relata 
sobre o conceito das tecnologias assistivas na perspectiva da acessibilidade. O terceiro tópico discorre sobre a Educação inclusiva no contexto da Tecnologia Assistiva, quarto tópico aborda sobre Direitos Necessários para Inclusão e as Tecnologias Assistivas e o quinto e ultimo tópico retrata sobre a Inclusão Educacional: Desafios e Necessidades.

\section{Conceituando as Tecnologias Assistivas}

Os países e continentes estão quebrando paradigmas em relação a esse assunto que ao longo do tempo vem sendo discutido entre ambos. Mesmo com tantas discussões relacionadas ao tema em questão. Á uma grande perspectiva de que todas as Leis que se referem à acessibilidade, e tecnologia assistiva sejam realmente cumpridas.

Formular um conceito de Tecnologia Assistiva, também chamadas de Ajudas Técnicas, sendo ainda um assunto bastante recente ainda esta atravessando varias etapas e fases, estando em pleno desenvolvimento para um real conceito.

È fundamental o papel da família no estimulo ao cumprimento dessas Leis sendo que a família é o primeiro contato que a criança tem e é através da família que se percebe algo de anormal nas crianças que venha a ter algum tipo de deficiência. Segundo GALVÃO (2005). Relata que:

[...] Tecnologia Assistiva é área do conhecimento, de características interdisciplinar, que engloba produtos, recursos, metodologias, estratégias, praticas e serviços que objetivam promover a funcionalidade, relacionada á atividade e participação de pessoas com deficiência, incapacidades, ou mobilidade reduzida, visando sua autonomia, independência, qualidade de vida de inclusão. (GALVÃO,2005,pg. 10)

Baseada no que diz o autor, todos esses recursos são direitos que assistem as pessoas com deficiência, seja ela qual for. Com isso as famílias juntamente com as instituições escolares, devem fazer a lei que assegura esse direito, que é de suma importância para o melhor desempenho das pessoas com algum tipo de deficiência.

O conceito de Tecnologia Assistiva (TA), nesses últimos anos, vem sendo reformulado devido a importante abrangência, que essa área está tomando diante da inclusão de pessoas que necessitam dessas técnicas modernas e de grande valia para as pessoas que precisam de assistência. 
Foi criado há pouco tempo um Comitê de Ajudas Técnicas da Coordenadoria Nacional para integração de pessoas com deficiência onde deliberou que os recursos da Tecnologia Assistiva não se restringe somente para a sala de aula e sim para toda instituição escolar,onde a criança deve ser assistida durante o tempo que for ser necessário. Sendo de responsabilidade do professor e toda comunidade escolar determinar um local exclusivo e inclusivo para as crianças. Segundo a cartilha realizada pelo Conselho Nacional relata que:

[...] A Abrangência do conceito garante que a Tecnologia Assistiva não se restringe somente a sala de aula, mas estende-se a todos os ambientes da escola propiciando o acesso e a participação efetiva de todos os alunos e durante todo o tempo. o professor e toda equipe da escola tem a responsabilidade da construção de um ambiente acessível e inclusivo. Eliminado as barreiras arquitetônicas e atitudinais. (CNA, 2008, pg. 11)

Portanto existe mecanismos que podem ser reformulado, como por exemplo os espaços para a adequação e melhoria dos trabalhados, realizados no espaço escolar para minimizar a carência dessas pessoas que ainda sofrem com preconceitos e falta de acessibilidade não só nas escolas mas em alguns locais.

Neste contexto a Tecnologia Assistiva é resumida a toda e qualquer recuso que tem por finalidade tornar independente pessoa com deficiência dificuldades, qualquer acessório, objetos entre outros, que facilitem a aprendizagem das pessoas com deficiência.

Ressalto ainda que deficiências existem e que todos os profissionais em educação devem está aptos a conhecer cada uma delas, e para cada tipo de deficiência, existe um tipo de tecnologia adequado para melhoria do seu aprendizado e desempenho em sala de aula. Dos tipos de deficiências os mais comuns são: Deficiência visual que o professor por sua vez deverá entender e saber que o brailler, para facilitar a aprendizagem do aluno com esse tipo de deficiência. Deficiência Intelectual que a cartilha de Inclusão ressalva o seguinte: que o professor deve obter juntos os pais do aluno com (DI) informações fundamentais para elaboração de um plano de aula acessível para ele. Educar alunos com (DI) requer esforço consciente. Deficiência Auditiva, Motora, TEA, TDH, dislexia e etc.

\section{A Educação inclusiva no contexto da Tecnologia Assistiva}

Não podemos definir como ajuda técnica somente os objetos e os recursos, equipamentos, ou dispositivos, para executar as tarefas referentes às pessoas com deficiências, 
sendo que tudo que for utilizado será de grande valia para o desenvolvimento dos mesmos o homem tem a capacidade de ampliar seus conhecimentos em tudo, inclusive para melhoria de qualidades educacionais e nossas capacidades físicas.

Mesmo com a comunicação escrita o papel, a caneta, a criação do alfabeto, "tudo isso é tecnologia". E tudo isso esteve sempre muito, próximo do ser humano e de suas necessidades Galvão (2009) relata que:

[...] as tecnologias estão presentes em cada uma das pegadas que o ser humano deixou sobre a terra, ao longo de toda a sua história. Desde um simples pedaço de pau que tenha servido de apoio, de bengala, para um homem no tempo das cavernas, por exemplo, até as modernas próteses de fibra de carbono que permitem, hoje, que um atleta com amputação de ambas as pernas possa competir em uma Olimpíada, disputando corridas com outros atletas sem nenhuma deficiência (GALVÃO FILHO, 2009, p.38).

Podemos ver a tecnologia presente desde o surgimento da espécie humana, através da criação de ferramentas, pelo homem, a fim de suprir suas necessidades e tornar a vida mais fácil. Por exemplo: o fogo para aquecer o frio e cozinhar alimentos, mais adiante é usado para armas de fogo e hoje, temos bombas nucleares capazes de destruir parte da humanidade. Isso prova que as técnicas são constantemente imaginadas, recriadas e reinterpretadas, formando cultura e sociedade. Portanto, podemos afirmar que existem número incontável de tecnologias, dentre elas podemos citar as Tecnologias Assistivas, favorece a acessibilidade e o desenvolvimento de habilidades, para aprendizagem do aluno com necessidade educacional especial. Muitas vezes, estes recursos tecnológicos estão próximos ao nosso dia-a-dia e passam despercebidos, ora outros à tecnologia avançada que auxiliam o portador de deficiência no contexto educacional, softwares de comunicação alternativa e aumentativa, recursos de mobilidade pessoal, teclados virtuais com varreduras e acionadores, mouses diferenciados, textos ampliados, textos em Braille, textos com símbolos, mobiliário acessível, lupas todos esses recursos são referente a Tecnologia Assistiva, que favorece a acessibilidade e o desenvolvimento de habilidades para aprendizagem do aluno com necessidade educacional especial.

\section{Direitos necessários para inclusão e as tecnologias assistivas}

Promover e colaborar com a sociabilidade é papel do professor, que é mediador do conhecimento. Portanto a inclusão se faz necessária no cotidiano escolar, é na escola que a 
criança aprende a se socializar com outras crianças através das brincadeiras proposta em sala. O emocional é eficaz para a criança que se relaciona com a percepção da própria capacidade, de lidar com outras pessoas do convívio, monitorando e planejando a mudança dos sentimentos, adversos que inibem a persistência da busca pelo o seu objetivo.

A Lei de Diretrizes e Bases da Educação 9394/96, expressa a concepção integracionista da educação especial como modalidade substitutiva ao ensino regular, com isso é de grande relevância fazer-se cumprir esse direito escrito na lei. No entanto infelizmente ainda existe uma rejeição significativa no que diz respeito à inclusão no Brasil. Na articulação entre a escola e a inclusão da criança, vale ressaltar vários pontos, pois mesmo sendo direito da criança essa inclusão ainda não se é cumprida como deveria. Em dois de dezembro de 2004, foi aprovado um decreto federal de $n^{\circ} 5.296$, onde garante a acessibilidade em todos os âmbitos. Ele define, em seu artigo $8^{\circ}$, o que é acessibilidade, ajudas técnicas e desenho universal, ressaltando que: -

[...] acessibilidade, conclusão para utilização, com segurança e autonomia, total ou assistida, dos espaços, mobiliários e equipamentos, urbanos, das edificações, dos serviços, de transportes e dos dispositivos, sistemas e meios de comunicação e informação, por pessoas portadoras de deficiência ou com mobilidade reduzida. ( CARTILHA, 2008,p. 10)

A linha de ação sobre Tecnologias Assistivas indagam que a escola é o meio mais propicio para o combate as atitudes de discriminação e que é necessário encontrar varias técnicas e métodos para que essa inclusão seja aceita, e no que diz respeito à educação os profissionais que negarem esse direito, deverão ser punidos de um a quatro anos de reclusão e multa.

O princípio fundamental desta linha de ação é de que as escolas devem acolher todas as crianças, independentemente de suas condições físicas, intelectuais, sociais, emocionais, linguísticas ou outras. Devem acolher crianças com deficiência; que vivem nas ruas e crianças que trabalham; crianças de população distantes ou nômades; criança de outras etnias e crianças de grupos desfavorecidos. (BRASIL, 2008, p.1718).

Valendo-se dessas hipóteses, não importa a classe social, ou seja, o que for, todos são iguais perante a lei, portanto a inclusão de crianças com algum tipo deficiência tende a ser prioridade. Inserir uma criança especial em escolas regulares requer bastante paciência e dedicação por parte da escola e da família, pois nem todas as instituições abrem as portas para esses alunos. 
Algumas instituições se defendem, alegando não ter profissionais qualificados nem equipamentos e recursos especializados, ressaltando ter um alto valor, sendo que no artigo 25 da Constituição Federal que o direito é de todos mais o dever é do Estado e da família e não de outra pessoa física ou jurídica, entretanto o custeio desses gastos é do Estado e do Poder Público, que deve financiar o que for necessário para o desenvolvimento da criança com deficiência, esse direito é assegurado e custeado, com a finalidade de promover o atendimento educacional especializado, segundo o Ministério da educação (MEC/ 2008) o capital é usado para:

Implantação da sala de recursos que é de direito da criança ter uma sala específica para o seu atendimento. Formação de gestores, educadores e demais profissionais da escola para educação inclusiva. Adequação arquitetônica de prédios escolares para a acessibilidade, acesso aos mesmos materiais que as outras crianças usam, na sala de aula.

Vários instrumentos de avaliação, que a avaliação escrita tradicional não é suficiente para medir o desenvolvimento de todos os alunos e participar das atividades na escolares.

Ao iniciar o processo de inclusão escolar se faz necessário a busca por parcerias, sendo que esse processo se inicia muitas vezes, entre professor, pai e mãe, mas não podemos de forma alguma "calar-se" diante dessa situação, precisamos ir atrás, participar de reuniões, organizar projetos, ser ativo de alguma forma para o bem estar das crianças.

Quando a criança não é aceita na escola, que é um lugar acolhedor, se torna difícil os demais acessos, a escola é um local que a criança vai se interagir com outras crianças da sua faixa etária, se comunicar, brincar e se envolver em mundo todo seu. Mais para que isso aconteça dinamicamente o ambiente escolar precisa ser acolhedor, para que a criança sinta-se em casa.

Formar uma equipe multiprofissional, com o intuito de organizar um planejamento pedagógico, e preparar as pessoas que conviverão com estas crianças aumentam a lista de exigências que levam algumas escolas particulares a recusar alunos especiais. Além disso, deve haver um projeto dirigido a esses alunos, composto por representantes de diferentes áreas, como fonoaudiólogos, neuropsicólogos, neurologistas, terapeutas ocupacionais dentre outros, além de representantes pedagógicos da escola, sendo de suma importância ter uma equipe de profissionais qualificados para um trabalho benéfico as crianças que precisam de um acompanhamento.

O aprendizado e o desenvolvimento da capacidade de se relacionar dependem, de oportunidades de interação com crianças da mesma idade ou de idades diferentes em situações 
diversas, promover atividades individuais ou em grupo, respeitando as diferenças e estimulando a troca entre as crianças.

\section{Inclusão Educacional: Desafios e Necessidades}

É importante, para o educando, a reflexão sobre a inclusão de pessoas com algum tipo de deficiência, reconhecendo que são direitos escritos em lei que as pessoas portadoras de necessidades especiais deverão ser assistidas por órgãos competentes e inclusos na escola e na sociedade. Em tempos passados esse direito não existia sendo, que se nascesse alguma criança com "deficiência", seriam sacrificadas, escondidas da sociedade, isso dificultou um pouco a criação das leis que com o passar dos tempos foi concedido esse direito de inclusão.

Uma educação de qualidade deve ser acessível para todos sem descriminar ou excluir alguém de seus direitos. Ter a definição de uma educação inclusiva é sustentar, uma educação em que a heterogeneidade do grupo não é um problema, mas um grande desafio aos profissionais de educação TEODORO: (2006).

Falar de educação inclusiva é também falar de aprendizagens dentro da sala, as brincadeiras propostas devem ser ricas em movimentos para que atraia o aluno em participar, não é brincar por brincar mais brincar para se desenvolver, com prazer e dedicação adquirindo um objetivo, pesquisando e realizando brincadeiras adequadas para este fim.

$\mathrm{Na}$ educação infantil as brincadeiras, devem aglomerar todas as crianças, com a finalidade de promover a socialização entre ambos, pois nesta fase da vida as crianças necessitam experimentar vários tipos de movimentos para ter a sensação de liberdade e de capacidade onde conseguem através do divertimento a alegria de conquistar o espaço todo seu, sendo intermediado por seu professor, tendo a euforia e a satisfação da sua participação nas brincadeiras realizadas no âmbito escolar.

Refletir sobre a inclusão demanda uma série de assuntos que precisam ser analisados, estudados e pesquisados já que uma criança portadora de autismo ou de outro tipo de "deficiência" ao serem incluídas na escola necessita e é um direito seu de um professor capacitado para lhe auxiliar em todas as atividades propostas em sala, tendo ainda todo um trabalho especifico com a turma para que a criança por algum motivo não sofra bulyng, ou outro tipo de discriminação, aceitando os limites e as dificuldades de cada criança como relata o autor quando diz que: 
[...] Os limites, as capacidades, as dificuldades podem ser mostardas pelas expressões do próprio corpo, desenvolvendo sua inteligência exigindo certa organização perceptiva e estruturação do e do mundo. A partir daí, começa a ampliar seu espaço, explorando tudo que a cerca a parti das atividades perceptivos motoras que são essenciais ao seu desenvolvimento. (PICOLLO, 2012, p 37).

Ressalto ainda que em virtude da educação infantil ser uma fase importante para a alfabetização e interação da criança com o mundo e com ela mesma, o movimento é uma dimensão que deve ser produtiva e elaborada a cada detalhe ampliando de forma objetiva a cada parte do corpo, através das atividades perceptivo-motoras, explorando tudo que for essencial para o seu desenvolvimento diante das situações propostas para os movimentos corporais, assim conclui-se que a criança esta envolvida intimamente com o mundo em movimento com isso deve-se ser acompanhada desde os seus primeiros anos de vida integrando o autista de forma satisfatória em todos os movimentos respeitando seus limites de adaptação.

A criança autista é capaz de aprender, como as outras crianças, entretanto, se fazem necessárias à utilização de técnicas e intervenções que facilitem e esse processo, considerando as características e especificidades do modo de ser e estar no mundo dessa criança que necessita dessa socialização com outras crianças para melhor se desenvolver.

Segundo estudos, apontam que os atendimentos de estudantes com deficiência ou necessidades de educacionais especiais evoluíram, pois em um período de quatro anos, aconteceu um aumento significante nas escolas, sendo que em relação a capacitar os profissionais em educação para essa evolução foi insignificante bem como a adaptação dos espaços escolares para receber essas crianças, seja no espaço físico,pedagógico, educacional.

Entretanto, o desafio não está somente nas características da pessoa com deficiência ou no diálogo entre família e educador. A viabilização financeira dos métodos especializados de ensino também é uma necessidade que e é dificultada por serem de alto custeio. "por meio deles, é possível reduzir a incidência de comportamentos inadequados e ajudar a criança na organização do seu cotidiano" bem como facilita seu ingresso em alguns espaços e na comunicação com os colegas e professores.

[...] As pessoas com deficiência não sejam excluídas do sistema educacional geral sob alegação de deficiência e que as crianças com deficiência não sejam excluídas do ensino fundamental gratuito e compulsório, sob a alegação de deficiência e que as pessoas com deficiência possam ter acesso ao ensino fundamental inclusivo de qualidade e gratuito. (PEREIRA, 2010, p 20). 
Os desafios encontrados são muitos, mas não podemos desistir e lutar para que várias coisas ainda sejam conquistadas e realmente termos uma inclusão e uma educação de qualidade, tanto para essas crianças que precisam ser inseridas na escola e na sociedade.

Formar uma equipe multiprofissional, com o intuito de organizar um planejamento pedagógico, e preparar as pessoas que conviverão com estas crianças aumentam a lista de exigências que levam algumas escolas particulares a recusar alunos especiais. Além disso, deve haver um projeto dirigido a esses alunos, composto por representantes de diferentes áreas, como fonoaudiólogos, neuropsicólogos, neurologistas, terapeutas ocupacionais dentre outros, além de representantes pedagógicos da escola sendo de suma importância ter uma equipe de profissionais qualificados para um trabalho benéfico.

\section{Considerações Finais}

Esta pesquisa teve a intenção de contribuir para esclarecimentos de como as Tecnologias Assistivas tem participação importante no desenvolvimento da criança com algum tipo de deficiência, contribuindo com relevância para a formação do ser social e pessoal, é através das técnicas de ajuda que a criança com deficiência tem uma assistência para o seu desenvolvimento psíquico,motor, físico e social, contribuindo para o favorecendo da inclusão na sala de aula e fora dela, pois ao participar sem rejeição das atividades o aluno senti-se útil em todos os aspectos.

A inclusão amplia as reflexões de que diferente não é a criança e sim o jeito e o modo de como a sociedade a ver, a criança com deficiência não tem culpa de ter nascido assim, ninguém tem culpa, até agora não existe um culpado, seu desenvolvimento é diferente das pessoas consideradas "normais", mais isso não impede que a criança participe de toadas às atividades proposta na sala de aula e no ambiente em família, sendo que tenha um espaço exclusivo para essas pessoas. Através das brincadeiras e do uso das Tecnologias Assistivas a criança aprende a se socializar-se de forma dinâmica e prazerosa.

Intensificando-me através dos estudos realizados de que o brincar, o brinquedo favorito e a brincadeira tem uma contribuição favorável para o desenvolvimento psíquico, intelectuais, mental, cultural e físicos, superando desafios e divertido-se em todos os aspectos.

Esta visão instigou-me a pesquisar sobre esse assunto que abrange vários sentidos, e que as tecnologias Assistivas necessita de vários órgãos para serem cumpridos corretamente, 
utilizar esses recursos desenvolve de forma significativa a criança, sendo cabível ao professor se apropriar de um local adequado para realização das atividades propostas.

Contudo, foi de grande relevância, além de aprimorar meus conhecimentos tendo um olhar mais intenso no desenvolvimento da criança, na inclusão e no uso das tecnologias assistidas.

Ficou explicito que a nova tecnologia desenvolve e ajuda a criança com deficiência estando vinculado a uma prática valiosa de ensinar, incluindo todas as crianças com deficiência, ou que venha a ter algum tipo de mobilidade.

Educar-se em relação a novas técnicas de acesso, para melhoria das pessoas com algum tipo de deficiência, é enriquecer seus conhecimentos para melhor atuar, em salas de aula de Ensino Regular, onde as crianças são inseridas e necessitam de um acompanhamento especializado e de qualidade. Sendo cabível ao professor fazer essa ponte, entre a escola, família e seus direitos. Fazendo valer seus direitos.

\section{Referências}

ANTUNES, Z.R. de. Educação Infantil: fundamentos e métodos. São Paulo: Cortez Editora 2006.p.02, p.06.

BRASIL, Ministério da Educação Especial. Secretaria da Educação Especial. Decreto ${ }^{0}$ 6.571/2008. Brasília. MEC, São Paulo, 2008.

BRASIL. Ministério da Educação. Lei de Diretrizes e Bases da Educação Nacional. MEC, 1996.

BRASIL. Lei de Diretrizes da Educação- Lei n ${ }^{\circ}$ 9.394/96 de 12/12/2012

BRASIL, Ministério da Educação Inclusão. Revista da Educação Especial vol.4, $\mathrm{n}^{\circ} 1$. Brasília: MEC, São Paulo, 2008.p.17-18

GALVÃO FILHO, T. A.Tecnologia Assistiva para uma escola inclusiva: apropriação, demandas e perspectivas. 2009. 346f. Tese (Doutorado em educação) - Faculdade de Educação, Universidade Federal da Bahia, 2009.

KLEIMAN, Ângela. Da leitura Texto e leitor: aspectos cognitivos da leitura. $8^{\mathrm{a}}$ ed. Campinas, São Paulo: Pontes, 1989

MIRANDA, Simão . Do fascínio do jogo à alegria do aprender nas séries iniciais. Campinas, SP: Papirus, 2006.p.35 
PICOLLO, Nista, Vilma, Lení. Corpo em movimento na Educação Infantil. Editora Tellos. $1^{\circ}$ Edição. São Paulo 2012. P.30

\section{Como citar este artigo (Formato ABNT):}

ALENCAE, Simone dos S.; FRANÇA, Aurenia P de. Tecnologia Assistiva para uma Escola Inclusiva: Desafios e Perspectivas . Id on Line Revista Multidisciplinar e de Psicologia, 2017, vol.11, n.38, p. 541-552. ISSN: 1981-1179.

Recebido: 01.10.2017

Aceito: 03.11.2017 